\title{
Apuntes para una economía política \\ del cuerpo y la ciudad
}

Marco A. Jiménez*

\begin{abstract}
Mi investigación desemboca en el resultado de que, tanto las relaciones jurídicas como las formas de Estado no pueden comprenderse por sí mismas ni por la llamada evolución general del espíritu humano, sino que radican, por el contrario, en las condiciones materiales de vida [...] y que la anatomía de la sociedad civil hay que buscarla en la Economía Política.
\end{abstract}

Marx

Resumen: El texto que se presenta hace una reflexión que coloca la cuestión de la identidad y la diferencia en el ámbito de un posible análisis del cuerpo y la ciudad bajo la perspectiva de cierta concepción de la economía política. En especial se reflexiona desde la noción de totalidad. La idea principal es que el cuerpo y la ciudad no son cosas distintas, que la ciudad no es simple creación de urbanistas, ingenieros y arquitectos así como el cuerpo no es obra de médicos y pedagogos.

Palabras Clave: identidad, diferencia, totalidad, economia politica, cuerpo, ciudad.

Presentación

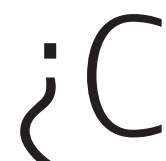

ómo formular una idea a contracorriente cuando esta época está llena de simulacros y apariencias que nos presenta las cosas como si fueran diferentes o extraordinarias, como sacadas del sombrero de un mago que nos hace creer que allí habitan el conejo y la paloma? Todos sabemos que esto es imposible, aunque si queremos divertirnos hay que aceptarlo; se trata de un como si, de una suspensión de la incredulidad que, más allá de estar relacionada con una creencia mítica y un devenir trágico, asume la vida como un melodrama y una indiferencia práctica.

Decía un colega que las ciudades actuales son tan plurales, dinámicas, multiculturales, tanto como las coloridas fotos que colocan en Face Book los jóvenes. Para mí no hay nada más aterrador, indiferente y estático que esas fotografías donde los jóvenes se muestran con las mismas posees, sonrisas, ropas, ademanes y mensajes.

Hay quien supone que las relaciones colectivas son líquidas, que vivimos en una época de vacío donde cada quien se acomoda como puede o como quiere, que incluso esa

\author{
* Profesor de \\ la Facultad de \\ Estudios Superiores \\ Acatlán-Unam, \\ y del posgrado en \\ ciencias sociales \\ $\mathrm{y}$ humanidades \\ de la UACM. \\ <marcoacatlan@ \\ gmail.com>. Marco \\ A. Jiménez (Ed.), \\ Investigación \\ educativa. Huellas \\ metodológicas, \\ México, Juan Pablos \\ - Seminario de \\ Análisis de Discurso, \\ 2012.
}


es una gran ventaja de nuestras libertades individuales. ¡Por fin logramos el sueño de los viejos comunistas, no hay sociedad más igualitaria que la nuestra! Aunque las mercancías que usemos sean originales, chinas o piratas, la cultura del nuevo capitalismo nos hace creer que todos estamos al alcance de casi cualquier cosa que deseemos. Si las ciudades son por excelencia el lugar del sexo y la política, por supuesto que son el lugar de los cuerpos ¿qué política y qué sexo se podría consumar sin cuerpos? Sin embargo, sexo, política, cuerpo y ciudad no siempre se han conformado del mismo modo. Tenemos por ejemplo: la Grecia de la democracia, la Roma imperial, el Medioevo europeo, la Europa victoriana, el mundo prehispánico, la llustración y la contemporánea globalización.

Hoy, en apariencia, somos más libres que antaño, nos movemos más o menos de un lugar a otro con cierta facilidad o en condiciones que antes no existían, ya no en, digamos, la red de internet que nos traslada en un instante a cualquier parte del mundo. Por ejemplo los centroamericanos migran con mayor fluidez hacia los Estados Unidos a través de territorio mexicano, los gitanos húngaros o rumanos pululan en las calles de España en mayor cantidad, la pornografía infantil y el tráfico de seres humanos se hace con rapidez vía internet, en fin, éstas y otras son las cosas que hacen pensar que hoy tenemos experiencias corporales, sensoriales directas o virtuales con mayor libertad.

Nuestros hijos y nietos están convencidos que ellos son más libres que lo que fuimos nosotros o nuestros abuelos. Que ellos lo crean es hasta cierto modo comprensible, pero que nosotros o, más aún, nuestros abuelos piensen que eso es una verdad universal, creo que al menos debiera de ser motivo de análisis. Ahora no podemos afirmar con facilidad, como antes se hacía, que "todo tiempo pasado fue mejor" porque aparte de ser políticamente incorrecto es muy difícil de demostrar frente a los "beneficios" científicos tecnológicos y la vida "democrática".

Lo que en este breve texto se quiere cuestionar es la pertinencia de la posible relación entre un análisis que, reinterpretando algunas de las categorías de la economía política marxista, permita comprender el actual vínculo entre cuerpo y ciudad. Es verdad que algunos marxistas redujeron sus reflexiones sobre lo que se denominaba la superestructura social al determinismo de la estructura económica, ésta fue la explicación preponderante durante años.

En la actualidad hay un ánimo que pareciera favorecer la diversidad de posiciones que van desde el sentido común hasta una aparente fundamentación científica o humanista que transita entre las veleidades de conceptos sacados como de una bolsa de payaso, que toman lo que algunos entienden de las llamadas neurociencias o de la mecánica cuántica para explicar lo individual y lo social, o por otra parte la acomodaticia e ideológica comprensión multiculturalista del mundo. Lo que parece una atractiva y 
multifacética Torre de Babel no es otra cosa que una camisa de fuerza ideológica, política y económica que ofrece una concepción sistemática, única y unificada del mundo.

En la actualidad conocemos algunos planteamientos sociológicos que resaltando aspectos de género, de creencias religiosas, de modas, de comportamientos individuales o colectivos, de afectos y sensibilidades personales, de adscripciones a movimientos o concepciones ecologistas, defensoras de derechos humanos, de derechos de infantes, de derechos de los animales y en fin un sin número de nobles causas, explican o intentan comprender lo social, negando por principio alguna reflexión de carácter universal, se privilegia en esos estudios la descripción de acontecimientos o de objetos sin la más mínima reflexión crítica.

Cuando por ejemplo, se habla de economía, aunque sean pocos los que entienden del asunto, se informa de las variaciones de las bolsas de valores mundiales, del costo del barril de petróleo, de los problemas del desempleo, de las crisis financieras, pero no se piensa desde una perspectiva política, y no entendiendo política como simple gestión administrativa de lo ya existente, sino como la capacidad de crear, pensar y articular aquello que parece imposible.

Como lo sugiere la epígrafe que anuncia este texto, en esta época pretendemos conocernos a partir de las minucias de nuestra diaria vida, vale lo mismo un horóscopo que una sesión psicoanalítica que la opinión de un psicólogo, o da lo mismo una planta o infusión de algún té medicinal que un medicamento farmacéutico. Por la mañana se puede ser un apasionado defensor y usuario de alguna tecnología e incluso de las políticas que la hacen posible y por las noches un místico y refinado practicante de alguna escuela o grupo de yoga. En ningún caso establecemos algún tipo de relación que nos lleve a pensar que las diferencias con vecinos, colegas, familiares o incluso con uno mismo vayan más allá de aquellos conflictos particulares o locales, nos hemos hecho enemigos de nosotros mismos, nos tememos y confrontamos por cosas que aún muy reciente nos hubieran parecido completamente absurdas e irracionales. Y es entonces cuando se considera que los asuntos de la ciudad, de los colectivos o grupos sociales, que los problemas individuales pueden y tienen que alcanzar solución por vía jurídica, que es a través de las leyes como se deben resolver los problemas sociales, económicos y políticos. ¿Quién podría oponerse a esto? Formalmente nadie. En realidad vemos cómo muchas de esas leyes propician y promueven mayor violencia y conflicto por la sencilla razón de que la participación social es nula o se reduce a otros tantos formalismos.

Por lo anterior podemos afirmar que efectivamente las relaciones jurídicas, el escaso Estado que aún nos queda y lo que podríamos denominar el espíritu indolente, indiferente y violento de esta época tienen una íntima relación con las condiciones materia- 
les de vida. Dicho de otra manera, que el cuerpo social, sus regularidades y funciones, las significaciones sociales que nos hacemos de nuestras instituciones y de la sociedad en su conjunto, así como nuestras prácticas sociales e individuales están en íntima relación con la ciudad y sus objetos. Que, interpretando a Sennett, la carne y la piedra están implicadas. Que la alienación, la indolencia, la indiferencia, el miedo y la violencia son parte intrínseca del modo en que se construyen y presentan las calles, avenidas, espacios públicos y privados, tales como edificios, centros de recreación y comerciales.

No se trata simplemente de una mala planeación urbana o de una deficiente construcción de arquitectos o ingenieros. Los puentes, túneles, vías rápidas son equivalentes a partes de nuestro cuerpo físico, pero sobre todo están en relación con nuestros pensamientos y afectos. Pasar horas frente a una computadora en una oficina, un cubículo, una habitación tiene consecuencias no sólo psicosomáticas sino sobre todo existenciales, en nuestras prácticas sociales. Permanecer en vehículos de transporte público o particular, encerrados por varias horas al día tiene derivaciones en nuestra vida psíquica, individual y colectiva.

Dice Sennet con relación a los motivos que lo impulsaron a escribir su libro Carne y piedra. El cuerpo y la ciudad en la civilización occidental lo siguiente:

\footnotetext{
Me impulsó a escribir esta historia el desconcierto ante un problema contemporáneo: la privación sensorial que parece caer como una maldición sobre la mayoría de los edificios modernos; el embotamiento, la monotonía y la esterilidad táctil que aflige el entorno urbano. Esta privación sensorial resulta aún más asombrosa por cuanto los tiempos modernos han otorgado un tratamiento privilegiado a las sensaciones corporales y a la libertad de la vida física. Cuando comencé a explorar la privación sensorial en el espacio, tuve la impresión de que el problema se limitaba a un fracaso profesional: los arquitectos y urbanistas contemporáneos de alguna manera habían sido incapaces de establecer una conexión activa entre el cuerpo humano y sus creaciones. Con el paso del tiempo me di cuenta que el problema de la privación sensorial tiene causas más amplias y orígenes históricos más profundos (Sennett 2007: 17-18).
}

La ciudad y el cuerpo no son simples resultados de proyecciones urbanísticas o de políticas de desarrollo urbano tomadas por políticos, administradores y especialistas interesados únicamente en los recursos financieros, impactos electorales, ecológicos, sanitarios, educativos e insumos materiales para la construcción. Podríamos sumar una infinidad de aspectos a las decisiones que se toman sobre las ciudades y sus habitantes, pero la cuestión no es técnica o funcional, aunque así lo parezca. Tampoco las ciudades y los cuerpos son el resultado de microfísicas articulaciones y rupturas en el quehacer cotidiano y en la infraestructura material que en el momento menos 
pensado se dislocan y por generación espontánea producen nuevos seres y cosas. Hay una condición de totalidad y un tiempo que articula, tensa y desarticula el vínculo entre la ciudad y el cuerpo.

\section{Aproximación metodológica}

Parafraseando El método en la economía política de Marx (1971:41-51), podríamos decir que cuando se analiza la ciudad y el cuerpo, como referentes conceptuales que parecen remitir en principio a los límites urbanos de ciertas disposiciones arquitectónicas que por motivos territoriales, físicos y materiales difieren unas de otras, así como a los habitantes que pueblan dichas superficies, a sus edades, distribución por género, al modo en cómo se conglomeran. Puede parecer un buen método comenzar por la base sólida de lo que es real y concreto; en una palabra en enfocar los temas de la ciudad y el cuerpo a partir de sus condiciones materiales y de su demografía respectivamente. Bien mirado este método (siguiendo con Marx) es erróneo. Las condiciones materiales y de construcción de una ciudad, su ingeniería y arquitectura. Así como las formas de vida, costumbres, distribución de los habitantes; por edades, sexo, ingresos económicos, etcétera, es decir, su demografía, resultan una abstracción, si pasamos por alto, a quienes se encargan del mantenimiento, la limpieza, las obras, la administración de los recursos citadinos y del mismo modo cómo se concentra la propiedad en ciertas personas y otras carecen de lo más mínimo, de cómo se organizan para subsistir, cuánto ganan, sus afectos, etcétera. Sin embargo si empezaremos a estudiar la ciudad solo por su mobiliario urbano seguramente tendríamos una concepción equivoca del conjunto, o por el uso que hacen los niños de ciertas escuelas de sus aulas, sería insuficiente para comprender la totalidad.

Pero si procediéramos mediante un análisis cada vez más penetrante, llegaríamos a nociones cada vez más simples: partiendo de lo concreto que yo percibiera, pasaría a abstracciones cada vez más sutiles para desembocar en las categorías más simples. En este punto sería necesario volver sobre nuestros pasos para arribar de nuevo a las condiciones materiales de construcción y a los habitantes de la ciudad.

Se trata, por ejemplo, de la tarea de un cazador que a partir de la simple huella concreta de un león puede inferir aspectos más abstractos de su presa es decir, tamaño, género, tiempo en que estuvo en el lugar, su probable rumbo, etcétera, de aspectos abstractos, no visibles, sobre la existencia del león. Es como si en principio decidiéramos conocer una ciudad por el material que se usa para sus principales construcciones, por así decirlo, iniciar por los tabiques y para conocer sobre los cuerpos que la habitan empezar por los zapatos. Es así como comenzamos el estudio por lo más simple y concreto, un tabique y un zapato. Marx partió del estudio de la economía a través de la mercancía, una categoría simple, desde la cual creó, analizó e interpretó 
la complejidad del modo de producción capitalista, pudo haber iniciado su pesquisa en un alfiler, y de hecho así lo hace en algún momento, pero lo importante es que a ese objeto lo denomina mercancía, lo entiende dentro de un régimen de relaciones histórico sociales y no sólo en la simplicidad, en el sentido común que sus ojos le dan junto con la "inocente" mirada de los demás. "Lo concreto es lo concreto, ya que constituye la síntesis de numerosas determinaciones, o sea la unidad de la diversidad" (Marx, 1971: 42). Se trata de un proceso de síntesis del pensamiento, es un punto de llegada y no un punto de partida. Se trata de la representación que nos hacemos de la realidad. Es muy importante aclarar que representación es para nosotros (y esto ya no es Marx) una creación de la realidad, en donde esta creación sigue el principio del valor, es decir de la cantidad de trabajo socialmente necesario para la producción de un bien. La representación para nosotros es un valor en tal sentido. Nosotros partimos de la realidad, de la representación que nos hacemos de ella, sin embargo cuando la pensamos, esta realidad se convierte en punto de llegada, es decir, se produce un trabajo simbólico-imaginario de creación y no sólo de representación de la imagen o de construcción simbólica de piezas dadas de antemano de la realidad.

A la realidad podemos denominarla ciudad o cuerpo y sin embargo también se podría hablar de ella como urbanizaciones o suburbios. De hecho para algunos como Kosik (2012: 51-62) la mayoría de la población ya no vive en ciudades sino precisamente en urbanizaciones o suburbios. En su ensayo "El triunfo del método sobre la arquitectónica" se propone mostrar cómo es que la concepción cartesiana ha triunfado en nuestra modernidad al eliminar la diferencia creativa de la arquitectura de antaño frente a la identidad funcional de nuestras urbes. En tal sentido cuerpo y ciudad son recuperados como significantes vacios que habrá que crear, pero no como un acto exclusivo de la mente o de la inteligencia, no solo como un problema epistemológico, sino también desde ciertas condiciones histórico sociales, desde ciertos intereses.

Tal y como afirma Merleau-Ponty con relación al cuerpo, cuestión que puede ser extensiva también para nuestro concepto de ciudad:

\footnotetext{
Veremos que el propio cuerpo rehúye, en la misma ciencia, el tratamiento que se le quiere imponer. Y como la génesis del cuerpo objetivo no es más que un momento en la constitución del objeto, el cuerpo al retirarse del mundo objetivo, arrastrará los hilos intencionales que lo vinculan a su contexto inmediato y nos revelará, finalmente, tanto al sujeto perceptor como al mundo percibido (2000: 91).
}

Sin duda, la ciudad, la urbanización o el suburbio desde donde se percibe nos revela tanto al propio espacio desde donde se mira, como al propio cuerpo desde donde se es sensible. No como un punto de partida sino como un lugar de llegada en donde lo que se ratifica no es la armonía, la completud, la objetividad en la relación entre 
cuerpo y ciudad sino exactamente lo contrario, la irremediable tensión la diferencia constante, la imposibilidad de la conexión plena entre el asfalto y la piel.

\title{
Economía política. \\ Totalidad del cuerpo y la ciudad
}

Decir que no tenemos un cuerpo sino que somos nuestro cuerpo, es algo que se puede plantear cuando nos comprendemos como prolongaciones vivas del asfalto, del cemento, de los cables, de paredes, calles, avenidas, edificios y demás elementos de la ciudad. Somos la ciudad que vivimos, somos la carne ceñida por cemento y simultáneamente la piel que envuelve las cosas de la urbe. Como en la imagen profundamente metafórica que Revueltas nos describe en su novela Los días terrenales:

\begin{abstract}
Bautista y Rosendo caminaban a ciegas a lo largo de la vía del ferrocarril, con la propaganda bajo el brazo. A sus espaldas, sobre sus cabezas, en torno a sus cuerpos, unida a la piel como la malla de un bailarín, los rodeaba la negra ciudad sin límites, ahora tan absurdamente desconocida sin la dimensión ni la consistencia familiares, cardinales, que durante el día permiten establecerla (1996: 41).
\end{abstract}

Pensar la relación entre ciudad y cuerpo como una totalidad es algo que a ciertos profesionales del método etnográfico les podría parecer un despropósito, sobre todo si identifican la totalidad con la idea de un nomos, una regla universal o con lo absoluto, lo total o totalitario. Como señala Lefevbre,

es preciso cuidarse de confundir "total" y "totalitario", a pesar de que la confusión es bastante frecuente, provocando el descrédito de la reflexión filosófica, considerada fácilmente como sistemática, metafísica y totalitaria (2011: 106).

Por supuesto que la intención de incluir la cuestión de la relación entre ciudad y cuerpo como una totalidad también tiene un fin político y no puramente científico, filosófico o académico, como si esto último pudiera ser posible. No se trata de que como en la ciencia se aísle alguna molécula, germen o gen para luego extrapolar al universo los hallazgos de la experiencia y la razón. Tampoco de una reflexión que nos lleve más allá de lo formal para que por el camino de las costumbres o la ética transitemos a las características del juicio. Mucho menos en algo que en la actualidad se ha convertido en un modus vivendi de las ciencias sociales y humanas, la descripción al infinito del mundo, ya sean como discursos, representaciones o datos.

¿Qué es lo que olvidan los otrora viejos marxistas en sus puntillosas y antropológicas descripciones de actualidad? Quizás, que más allá de lo etéreo, evanescente, volátil, 
líquido y fluido de nuestras relaciones sociales éstas están configuradas sobre una profunda consistencia (materialidad), que aunque sea virtual, digital, cibernética no deja de incidir en aspectos tan diversos de la vida. Que esta consistencia cibernética del mundo es una economía política, una forma de producción, distribución y consumo de mercancías, donde el valor considerado como el trabajo socialmente necesario para la producción de un bien ya no habla solamente de una fuerza productiva por un lado y del capital por otro, sino de la profunda absorción que lo económico ha hecho de nuestro deseo, de nuestra voluntad. Hoy no solamente tenemos que trabajar en oficinas, comercios, industrias, etcétera, para vivir sino que nuestra voluntad se ha hecho mimética con las formas de administración, organización y gestión laboral. Pareciera que conciencia y mundo son una misma cosa; no hay diferencia, en todo caso hay indiferencia. Nuestro entusiasmo por la vida social e individual es tan efímero como un anuncio comercial de televisión.

La suma de las partes no hace al todo, como la totalidad al igual que lo universal no es la simple expresión de un particular hegemonizado. No hay que dejar de señalar que este empirismo descriptivo, de supuestas cualidades, sensibilidades o afectos, tan en boga en la sociología actual hace creer que la realidad que señalan así como el modo en cómo lo hacen (construyen) es la verdad, cuando lo que en realidad lo que en verdad hacen es convertir en conceptos lo que ellos dicen ver.

"La noción de totalidad es unidad y multiplicidad indisolublemente ligadas, constituyendo un conjunto un todo" (Lefevbre 2011: 106). La metáfora de Revueltas de la ciudad entendida como una malla que recubre el cuerpo de un bailarín es aún insuficiente, pues esta prenda no deja de ser un exterior y en realidad de lo que se trata es de un interior-exterior, la totalidad de la ciudad es como una banda de Moebius, lo mismo se está adentro que afuera. El binomio cuerpo-ciudad es un entrelazamiento tal como el de la banda que tiene bordes, y al mismo tiempo cuerpo y ciudad son como una botella de Klein, una superficie no orientable, sin bordes, sin fondo, entrada o salida.

Pensar la totalidad implica reconocer en el fenómeno o en el hecho social algo que está en él pero que no podemos vislumbrar. "Lo que es, no es todo" como diría Adorno, pero tampoco se trata de imponer a cosas, circunstancias o personas cualidades que no tienen, como lo hizo Marx con Europa, con la historia o con el proletariado. Como en el ejemplo de Lefevbre donde se pregunta "¿Qué pensaríamos de un zoólogo que dijera: este perro parece tener cuatro patas; pero en realidad no las tiene del todo o tal vez tenga cuatro millones" (2001: 107). Es en la imposibilidad de ver lo que hay en el fenómeno o incluso en el hecho social total, como Mauss Ilama a la totalidad, donde radica la cuestión política que aquí nos ocupa. 
Del mismo modo que intentamos recuperar la noción de totalidad, por decir lo menos, en términos heurísticos y metodológicos, parece pertinente reconocer que esta noción no tiene sentido si sólo se le quiere aplicar en el ámbito de la cultura, de la vida diaria, de nuestra voluntad y deseos sin considerar el modo en que se encuentra organizada económicamente la sociedad.

No se trata de volver a los viejos análisis marxistas deterministas, en donde lo económico resultaba la esencia de lo social, la causa. Hoy por lo contrario nos hemos olvidado de la organización económica del mundo o cuando se le piensa o se le refiere se asume como algo eterno e inmutable. Para entender qué es eso de la economía política y su importancia veamos lo que el propio Marx decía:

El resultado al que llegué y que, una vez obtenido, sirvió de hilo conductor a mis estudios, puede resumirse así: en la producción social de su vida, los hombres contraen determinadas relaciones necesarias e independientes de su voluntad, relaciones de producción, que corresponden a una determinada fase de desarrollo de sus fuerzas productivas materiales. El conjunto de estas relaciones de producción forma la estructura económica de la sociedad, la base real sobre la que se levanta la superestructura jurídica y política y a la que corresponden determinadas formas de conciencia social. El modo de producción de la vida material condiciona el proceso de la vida social, política y espiritual en general. No es la conciencia del hombre la que determina su ser, sino, por el contrario el ser social es lo que determina su conciencia. Al llegar a una determinada fase de desarrollo, las fuerzas productivas materiales de la sociedad entran en contradicción con las relaciones de producción existentes [...] (1973: 517-518).

Decir que la ciudad y el cuerpo son la base material en la que se desenvuelve el espíritu humano sería simplificar la referencia de Marx, por supuesto que hoy ese planteamiento de la estructura y la superestructura no ayuda mucho para entender la complejidad de nuestras relaciones y mucho menos para establecerlo como fundamento en el vínculo entre ciudad y cuerpo. Lo que interesa rescatar frente a esos estudios propios del multiculturalismo, frente a esos determinismos relativistas de una supuesta diversidad social, que sin duda es real, pero que obedece no sólo a las minucias de sus autenticas o aparentes diferencias, sino a una totalidad que nos remite a otras condiciones. Que si bien hoy podemos reconocer y vivir con lo diferente o ajeno a uno propio eso no significa que lo aceptemos como una comunidad de intereses que, como dice Sennett cuando habla de la diversidad cultural o étnica en Nueva York:

Los privilegiados se han protegido de los pobres como se han protegido del estímulo. Los necesitados han intentado llevar una es- 
pecie de armadura que sólo mantiene distanciados a aquellos que necesitan. La vida en Greenwich Village quizá ejemplifica lo máximo que hemos logrado: una voluntad de vivir con la diferencia, pero, al mismo tiempo, la negación de que ello implique un destino compartido (2007: 394).

La modificación de la estructura económica no depende de nuestra voluntad, ni siquiera de una u otra clase social, no es algo que se modifica por decreto, y cuando se hace hemos visto lo que sucede, pero también sabemos que si nos olvidamos del asunto, si atribuimos nuestras diferencias exclusivamente a cuestiones de edad, género, afinidades religiosas, gustos, etcétera, no llegamos a ninguna parte e incluso la violencia destructiva e irracional se incrementa.

Nuestro ser social transcurre unido al de la ciudad, dicho de otro modo, el estar en la ciudad es nuestro ser social, simultáneamente el ser de la ciudad está en nosotros. Como en la novela de Calvino, Ciudades invisibles. Cada ciudad con su territorio y materialidad es como la Ciudad de Dios de San Agustín, está en nosotros. Como Heine decía con respecto al nómada pueblo judío, que el territorio que habitaba estaba en la Torá.

Hablar de economía política y de la totalidad con respecto a la ciudad y el cuerpo de ninguna manera es un intento por volver a las certidumbres ideológicas del pasado, se trata de provocar a las certezas ideológicas del presente que desdeñan cualquier intento por pensar lo social e individual como un hecho social total o como totalidad y se quedan en la comodidad de los saberes psicológicos o del alma de un individualismo melancólico e indolente.

\section{Límites de la ciudad y el cuerpo}

La reflexión sobre la ciudad y el cuerpo impone una atención sobre la situación actual de dicha relación. Aún recientemente para reconocer las ciudades se establecía el contraste con lo rural, hoy parece que esa diferenciación entre lo urbano y lo rural ha dejado de ser tan clara y pertinente como antaño lo parecía.

Ir o venir del campo a la ciudad o viceversa permitía distinguir formas de vida cultural, económica y hasta políticas distintas. Había campesinos y citadinos, aquel viejo debate entre campesinistas y descampesinistas ha quedado resuelto. El campo ya no es nuestro campo, no sólo por una condición económica propia de la globalización y la forma de organización de la producción sino sobre todo por lo que de paisaje podría representar a los ojos de un urbano, por las formas de organización tradicionales, por los afectos expresados en modos propios de convivencia, es decir por diferencias culturales sustanciales entre lo que fue aquello que durante casi dos siglos denominamos lo rural y lo urbano. 
Había un mundo diferente al de las ciudades, fueran grandes o pequeñas, había algo distinto que se intercambiaba. Ahora cuando se habla del campo se hace referencia a un modo particular de procesar con avanzadas tecnologías los productos que de allí se obtienen, pero ni quienes los producen, distribuyen, comercializan y consumen provienen, promueven o conviven de modo distinto a quienes habitan las ciudades. Otra cosa es reconocer la existencia de comunidades indígenas con hábitos, lenguas, mitos y concepciones del mundo diferentes a las que predominan en las ciudades, sin embargo, aun en esas comunidades prevalecen formas de vida, organización y relación estrechamente vinculadas a las urbes.

La urbanización, cuya importancia crece sin cesar, transforma cuanto existía anteriormente. En estas torres metálicas que se elevan por encima de los bosques, frente a las montañas hay un desafío una interrogante. Desafío al pasado interrogante al futuro (Lefevbre 1978: 11).

Sin embargo, esta urbanización a la que refiere Lefevbre vio nacer un mundo que durante el siglo XIX y el XX no fue como él mismo afirma una simple enmienda al mundo anterior sino, "algo nuevo y distinto [...] lo urbano. Se vuelve la página. Otro texto social se escribe" (idem, 1978: 11). Es verdad, aparece algo distinto a lo rural que llamamos urbano, había un pasado y un futuro. Pero la pregunta que ahora nos hacemos, frente a un pasado inexistente o poco claro y ante un futuro cada vez más presente, ¿Qué es hoy aquello que da vuelta a la página, lo nuevo, a lo que conocimos en los dos siglos anteriores como urbano? Por así decirlo, lo rural se enfrentó a lo urbano. Lo urbano a qué nuevas condiciones se enfrenta en la actualidad, cómo nombrar eso distinto, diferente, nuevo en las relaciones entre la ciudad y el cuerpo en esta época. Definitivamente se ha alterado de manera global los modos en que se habita el mundo, aún en aquellas regiones de extrema pobreza.

Hoy decir que venimos al mundo de vida no deja de tener una especificidad muy clara, se existe, se es ahí, en una ciudad; miserable, pobre, rica, hermosa, grande, pequeña, pero al fin de cuentas ciudad. Hoy si aplica la expresión aquella de ser ciudadano del mundo, no hay otra forma de estar en él. El mundo se ha convertido en una gran ciudadela, o si se prefiere en un enjambre de ciudades, con sus bosques, lagos, desiertos, montañas y océanos, todo ello unido y separado por una red cibernética de cables y señales satelitales, a la que por cierto sólo unos cuantos tienen acceso. Lo anterior no significa que aquellos que carecen de los recursos tecnológicos de la época cibernética actual quedan al margen de los efectos que estos instrumentos y conocimientos producen. Es cierto, como plantea Sloterdijk, están fuera del Palacio de Cristal, sin embargo dicho Palacio o Sistema los produce y reproduce como indigentes del mundo, que por cierto no tienen nada que ver con la concepción de Ejército de Reserva o desempleados. 
Parece que el ser de la ciudad actual, su potencia, radica en su capacidad de producir insignificancia, indiferenciación, hastío, monología, en sus habitantes, pues como siempre, no se trata de una inocencia ingenieril o arquitectónica, lo sabemos desde Bentham hasta Blade runner pasando por Metropolis. Las ciudades no son entes neutros que están ahí esperando por nosotros para que con comodidad las habitemos, se modifican con nuestra sola presencia o ausencia, pertenecen a los muertos y a los que vendrán. Las urbes actuales están hechas de inmensas masas sólidas de cemento y asfalto, son absolutamente concretas y materiales y toda liquidez que les podamos atribuir, todo el carácter líquido o fluido de sus relaciones no puede dejar de lado sus materiales e históricas condiciones de existencia, es decir, de producción, distribución y consumo, pensar de otro modo puede conducir a un placentero y acomodaticio estado líqua o con cierta relatividad cínica nos podemos adaptar infinitamente.

En la ciudad actual gravitan dos promesas que como viejas ideologías de antaño publicitan y promueven con vehemencia las más avanzadas estrategias de la mercadotecnia las garantías de una vida segura y democrática, al alcance de todos, eso sí con diferentes costos. A la entrada de cada gran ciudad hay una marquesina que dice: Democracia y seguridad os harán libres.

El modelo de ciudad actual es la promesa de un universal que se puede vivir particularmente, con los mismos valores, las mismas leyes y las mismas cosas para todos, todo esto sustentado en un régimen de intercambio de mercancías, donde la más valiosa de ellas es el tiempo. El tiempo para dormir, para trasladarse, para trabajar, para tener placer, para descansar, para morir, se trata de un tiempo-dinero electrónico como la mercancía de mayor importancia, donde el deseo como apetito consciente de uno mismo no tiene cabida. No se desea desear, sino que se desean cosas, personas como cosas.

El reconocimiento de que lo que hace al mundo y a cada uno de nosotros no tiene ningún sentido en sí mismo, sino que cada uno y de modo colectivo dotamos de sentido al mundo y con ello a la ciudad no es lo mismo que la ignorancia de la insignificancia, la indolencia y la indiferencia. El mundo adquiere sentido por nuestros pensamientos y acciones, no son las cosas las que hacen deseable al mundo sino nosotros los que hacemos deseables a las cosas.

Dejar de significar y diferenciar individualmente puede ser un síntoma de autismo, ignorar que hemos perdido la capacidad de significar y diferenciar individual y colectivamente puede ser un grave síntoma de descomposición social, sin embargo, tener conciencia de ello, es decir de nuestra ignorancia en cómo significar y diferenciar el mundo, y actuar de lado de la insignificancia, es como dice Sloterdijk una conciencia cínica. Lo anterior garantiza tranquilidad, democracia y seguridad cínicas sólo equiparables con la apacible y doméstica vida de un vacuno corral. 
La ciudad y el cuerpo son dispositivos de control más que de disciplinamiento, de lo que se trata es que nos auto-regulemos que estemos autoconvencidos de que las cosas son así y no pueden ser de otro modo, de que la vida sigue igual.

\section{Conclusión}

Hasta aquí con la reflexión sobre el carácter insignificante e indiferenciador de la ciudad. Así como estoy convencido de lo anterior también lo estoy de que la ciudad actual no es nada más una jaula de hierro donde la irracionalidad campea a sus anchas. La ciudad es condición de realización de los cuerpos, lugar de su recreación, producción y circulación, espacio de creación, resistencia y fuga, lugar de ilusiones y fantasías, de alegría y tristeza, de amor y odio. El cuerpo a su vez es un cuerpo social, habitado por los claroscuros de la ciudad, es un cuerpo urbanizado, urbano. Es condición misma para la realización de la ciudad. Si como lo señala Sennet, ser hombre libre era sinónimo de habitar en la polis para los antiguos griegos, para nosotros la ciudad es origen y destino, pero también puede significar provocación y aniquilamiento. Esto lo ha sido para todas las generaciones que han habitado en lo que de un modo u otro hemos llamado ciudades. Incluso la gran Tenochtitlán fue la gloria y el infierno de su pueblo, la grandeza y la perdición de Moctezuma así como la Atenas del siglo V lo fue para los griegos y para Pericles.

El primero y último territorio habitado es el del cuerpo, éste es la medida con la que nos incorporamos al mundo de las cosas sensibles, pero sobre todo es aquello que permite diferenciarnos de los objetos y de los otros. La condición corporal nos diferencia de lo exterior, sabemos que hay un afuera que se roza con las epidérmicas fronteras. De manera simultánea el cuerpo indica un adentro, nos hace sentir fluidos, latidos y contracciones ajenas a nuestra voluntad, un interior autónomo. Cuando nacemos lo hacemos dos veces primero como masa biológica y luego como un ser. Cuando morimos quedan los restos y el ser se vierte en la memoria de los vivos, ya no es más para sí mismo. De la permanencia de los muertos, de su modo de acompañar a los vivos depende la propia vida de las ciudades, sus costumbres, sus placeres, sus dolores. Si la vida urbana fue lo que eliminó la vida rural, la vida cibernética, las capsulas tecnológicas, el ciberespacio es lo diferente de la vida urbana. La experiencia del cuerpo, la experiencia cibernética, anuncia nuevas relaciones con la vida y con la muerte, con el pasado y con el futuro.

Abstract: The text presents a reflection that places the question of identity and difference in the scope of a possible analysis of the body and the city from the perspective of a certain conception of political economy. In particular, it reflects from the notion of totality. The main idea is that the body and the city are not different things, that the city is not simply creating planners, engineers and architects as well as the body is not the work of doctors and teachers.

Keywords: identity, difference, totality, political economy, body, city. 


\section{Referencias}

HARDT, Michael; Negri Antonio. Imperio. Barcelona: Paidós, 2005.

KosIK, Karel. Reflexiones antediluvianas. México: Itaca, 2000.

LEFEVBRE, Henri. La noción de totalidad en las ciencias sociales. Telos, v. 13, n.1. Venezuela, Universidad Rafael Bello Chacín, Ene.-Abr. 2011, p. 105-124.

—. De lo rural a lo urbano. Barcelona: Península, 1973.

MarX, Carlos. El método en la economía política. México: Grijalbo, 1971.

MarX, Carlos; Engels, Federico. Obras Escogidas. Moscú: Ed. Progreso, 1973.

Merleau-Ponty, Maurice. Fenomenología de la percepción. Barcelona: Península, 2000.

ReVueltas, José. Los días terrenales. Madrid: Ed. Allca XX; Fondo de Cultura Económica, 1996.

SENNETT, Richard. Carne y piedra. El cuerpo y la ciudad en la civilización occidental. Madrid: Alianza Editorial: 2007. 